\title{
Breast Cancer Prevention and Treatment in Women with Severe Mental Illness
}

\author{
Mary V Seeman* \\ Department of Psychiatry, University of Toronto, Canada
}

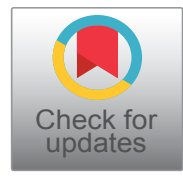

*Corresponding author: Mary V Seeman, MD, Professor Emerita, Department of Psychiatry, University of Toronto, 260 Heath St W, Toronto, Ontario, M5P 3L6, Canada, Tel: 1-416-486-3456, E-mail: mary.seeman@utoronto.ca

\begin{abstract}
Background: Breast cancer is an important cause of death in women with severe mental illness. Patient factors, provider factors, and social factors contribute to increased incidence and delayed diagnosis as well as delayed and substandard treatment in this population.

Method: This narrative review is based on the Google Scholar database from 2009 to the present, using the following search terms in combination with "schizophrenia", "psychosis", or "severe mental illness": Breast cancer, screening, chemotherapy, radiation, mastectomy, oophorectomy, chemoprevention.

Findings: Patient and treatment factors contribute to increased incidence. Despite the increased risk, breast screening uptake is low in this population, as is preventive surgery and chemoprotection. There are indications of treatment delays and also of treatment that is less thorough than that provided to mentally healthier peers. As a consequence of these factors as well as the prevalence of co-morbidity and low social support in this population, breast cancer mortality rates are high. Barriers to screening have been identified as patient apathy, cognitive deficits, and lack of information about breast cancer risks and options, vulnerability to stress, practical issues, poor communication between patients and care providers, and perceived stigma.

Conclusions: Based on the findings of this review, cutting the incidence and improving the prognosis of breast cancer in this population is potentially feasible. Information about risk factors for breast cancer needs to be made available to patients and psychiatric care providers. This will help to inform decisions about lifestyle factors and mental health treatments. Monitoring for co-morbidities and enabling screening procedures is essential. A close collaboration between oncology and mental health will help to ensure high quality care for breast cancer in women with severe mental illness.
\end{abstract}

\section{Keywords}

Breast cancer, Severe mental illness, Screening, Chemoprevention, Mortality

\section{Introduction}

Not only do individuals with chronic and severe mental illness disproportionally suffer from serious medical problems, but the quality of medical treatment they receive is often below par, and mortality rate is high. This is well known, and many of the factors responsible for this situation are known. First among the responsible factors is poverty, the consequence of long-term, highly stigmatized disabilities whose almost inevitable sequelae are life-long unemployment and social exclusion. Poverty governs where people live, what they eat, who their friends are, what they do with their time and what they do to keep healthy [1]. Poverty determines attitudes towards health, exposures to health threats, risk behaviors, and the response of health providers. Poverty also governs ease of access to medical care.

The second most important factor to influence the quality of health care among the severely mentally ill is the stigma that attaches to mental illness [2]. Stigma leads to social exclusion, depriving the mentally ill of sources of health information and negatively biasing the responsiveness of healthcare professionals.

The relatively small size of social networks and diminished family support of individuals with serious mental illness [3] means that they receive little advice or guidance about health matters from people they can trust [4]. Additional health vulnerabilities associated with severe psychotic illnesses are immune deficiencies that increase susceptibility to infection [5], a predisposition to diabetes mellitus [6], high rates of alcohol abuse [7], smoking [8] and accidental injury [9], compounding the risk for early mortality. People with severe mental ill-

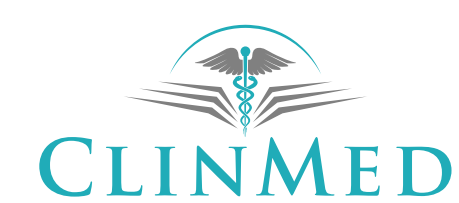

Citation: Seeman MV (2017) Breast Cancer Prevention and Treatment in Women with Severe Mental Illness. Int J Womens Health Wellness 3:064. doi.org/10.23937/2474-1353/1510064 Received: October 02, 2017: Accepted: November 25, 2017: Published: November 27, 2017 Copyright: (C) 2017 Seeman MV. This is an open-access article distributed under the terms of the Creative Commons Attribution License, which permits unrestricted use, distribution, and reproduction INTERNATIONAL LIBRARY in any medium, provided the original author and source are credited. 
ness are also exposed over the years to undue violence and abuse [10]; they suffer from cognitive deficits that make it difficult to accurately interpret the significance of medical symptoms [11], they often lack the motivation to seek medical care, and they are often fearful and suspicious of medical intervention [12]. Moreover, psychopharmaceuticals used to treat severe mental illness can themselves promote obesity and induce metabolic problems and cardiovascular disease that increases the mortality rate [13].

Overall mortality rates are very high in this population $[14,15]$. Ischemic heart disease and suicide are the most common causes of death, impacting men more than women. The next most common cause of death in persons with Severe Mental Illness (SMI) is cancer, which is more prevalent among women than men. Cancer prevalence rates in women with schizophrenia have been reported to be 491 per 10,000 while, in men with schizophrenia, they are estimated to be 226 per 10,000 $[16,17]$. The low cancer rates in men with schizophrenia may reflect under-diagnosis. The relatively high rate in women has been, for the most part, attributed to breast cancer [18].

In the general population, death from breast cancer has been reduced through regular screening and, consequently, early case finding. This may not, however, apply to the SMI population. In 2002, Druss, et al. [19] began to question the quality of preventive healthcare provided to individuals diagnosed with mental illness. A 2009 review of 27 studies in this area found that the level of screening services received by patients with mental illness was demonstrably lower than that of their peers [20]. For this reason, I undertook a review of the recent literature on uptake of screening for breast cancer among women with schizophrenia and related disorders, and on cancer outcomes following diagnosis.

\section{Method}

I searched the Google Scholar database (which includes Medline and Embase) from 2009, the date of the Mitchell, et al. article [20] onward with the following search terms: "breast cancer, screening, chemotherapy, radiation, mastectomy, oophorectomy, chemoprevention" in association with "schizophrenia" or "psychosis" or "severe mental illness". What follows is a narrative review of the findings.

\section{Breast cancer risk}

There is no general agreement in the literature about whether or not women with schizophrenia are at higher than average inherent risk for breast cancer, although there are many reasons to believe that this could be the case. An important additional risk factor is the psychopharmacologic treatment of psychosis. The long-term administration of antipsychotic drugs raises prolactin levels and induces obesity, two potential in- ducers of breast cancer [21]. In addition, other potent risk factors for breast cancer are more prevalent in the schizophrenia population than outside it: insulin resistance, dyslipidemia, smoking, alcohol abuse, reduced physical activity, low parity, and generally low levels of breastfeeding [22,23].

\section{Breast cancer screening uptake}

Despite the possibly increased risk, there is less than average uptake of breast screening among women with severe mental illness. This is true whether screening is done by regular manual physical examination or by mammography [24-27]. On average, approximately $25 \%$ of women in psychiatric care receive standard breast cancer screening. The greater the severity of mental illness, the greater the barriers to screening [28].

\section{Barriers to screening}

The main barriers to cancer screening in the schizophrenia population have been identified as:

a) The apathy and lack of motivation characteristic of schizophrenia patients acts as an obstacle to doctor visits and other health initiatives [29].

b) Lack of knowledge about locally available screening programs by both service users and mental health providers impedes effective screening. Many patients harbor wrong beliefs and unresolved concerns about cancer screening and many mental health providers are not familiar enough with available services to assist their clients [30].

c) Practical obstacles are lack of insurance, lack of a regular primary care physician, transportation problems, unduly long wait periods for appointments, lack of annual reminders. This population changes address frequently and may experience periods of homelessness that undermine regular screening [31].

d) Some patients with SMI struggle with cognitive challenges that make it difficult to appreciate health risks and to plan ahead effectively [32].

e) Many patients are dissuaded by past experience of painful screening procedures $[33,34]$.

f) Sometimes the lack of follow-through can be attributed to poor communication and lack of optimal collaboration between service user and health provider. Providers may attribute medical complaints to the patient's psychotic thinking and may, therefore, be less likely than they would otherwise be to refer patients to specialized treatment. This is referred to as "diagnostic overshadowing" [35]. Concern regarding the potential dangerousness of individuals with schizophrenia may also negatively influence medical care in that physicians and other health personnel hold unconscious biases against patients so diagnosed and prefer to avoid them [30,36,37]. 


\section{Genetic screening and counseling}

The risk for certain forms of breast cancer depends on the presence of predisposing genes, notably BRCA1 and BRCA2. Screening for these genes constitutes an initial assessment of risk, especially in women with a family history of breast cancer $[38,39]$. One would expect women with severe mental illness to be less willing than other women to subject themselves to a genetic screen because awareness of genetic risk is generally reported as low in this population [40]. Interestingly, a study on willingness to attend genetic counseling found no difference between women with and without mental illness [41]. Both groups of women were willing to attend counseling sessions to the same degree.

\section{Preventive surgery}

In women with a BRCA1/2 mutation, risk-reducing surgeries, such as bilateral mastectomy and premenopausal bilateral salpingo-oophorectomy, are associated with a significantly reduced breast cancer risk of up to $80 \%$ and $50 \%$, respectively [42]. Some women with a positive BRCA1/2 test, therefore, decide to undergo voluntary surgery to remove their breasts and ovaries. Health professionals leave these decisions to the woman and her family, although decision-making tools to help with complex decision-making have been developed [43]. It is important to note, however, that should a woman with schizophrenia decide to have her breasts removed, her doctors would in all probability question her judgment. They would worry that decisions by a woman with schizophrenia were made on the basis of delusions rather than on logic. Not taking a person's statement at face value because of their medical diagnosis, as Sanati and Kyratsous have argued [44] is a form of testimonial injustice [45], an example of the many discriminatory practices faced by individuals with severe mental illness.

\section{Chemoprevention}

An alternative to breast and ovary removal is a 5-year use of oral risk-reducing medications, such as Selective Estrogen Receptor Modulators (SERMs) or aromatase inhibitors [40]. The administration of SERMS reduces overall breast cancer incidence by $38 \%$. Breast tumors that are estrogen receptor positive respond best, by approximately $51 \%$ and the preventive effect is calculated to last for 20 years after stopping. Aromatase inhibitors, which have a different side-effect profile than SERMS [46], are also effective, but less so than SERMS in premenopausal women $[42,47]$. The uptake of SERMs and aromatase inhibitors has been generally low because of the potential for significant side effects, which can include stroke, pulmonary embolism, deep vein thrombosis, and endometrial cancer. A second often mentioned reason for low uptake is the lack of communication with clinicians - failure to have questions fully answered, not knowing how long one needs to follow the regi- men, concerns about being randomized to ineffective prevention in clinical trials [48]. Uptake in women with severe mental illness has not been studied because these women have been excluded from clinical trials of chemoprevention in breast cancer, another example of prejudicial treatment [49]. Patients with SMI are often excluded from clinical trials because they are considered to possess insufficient decisional capacity.

\section{Treatment delays}

Once a diagnosis of breast cancer is made, there can be delays in starting treatment; delay of this sort have been demonstrated for women with pre-existing mental illness who are elderly [50]. In this study, treatment delay was found for the lead up time to surgery after a diagnosis had been made, and also for the time to chemotherapy following surgery [50]. People with severe mental disorders have relatively poor survival rates after a cancer diagnosis and this is true independently of cancer stage at the time of diagnosis and independently of all other potential confounders [51]. This suggests that the relative uptake of breast screening may not be the crucial factor. The positive association between mental disorders and cancer mortality are more likely to be accounted for by differences in survival after cancer diagnosis than by delayed diagnosis.

\section{Treatment concerns}

Survival after a cancer diagnosis depends to a large extent on the timeliness and quality of surgical treatment, radiation, and chemotherapy. For this reason, it is important to note that psychiatric patients in Australia have been reported to receive fewer chemotherapy sessions and less radiotherapy than patients without mental illness [52]. They also have been found to suffer more postoperative complications, and to have less access to palliative care compared to their peers [36]. This may be because women with severe mental illness are more likely than others to refuse or delay treatment, to miss appointments, or to drop out of treatment $[53,54]$. A Swedish study, however, has suggested another explanation - that, for patient, provider, and health system reasons, the healthcare provided to psychiatric patients is of lower quality than that provided to less stigmatized others [55].

\section{Mortality}

The mortality rate from breast cancer is higher among women with schizophrenia than it is among the general population of women. This may be result of a combination of factors - the relative lack of screening leading to more advanced disease at the time of diagnosis, the delays and interruptions in treatment once the diagnosis is made, or the substandard quality of medical care provided to this population [53]. Whatever the reason, $15 \%$ of cancer deaths can be attributed to the interaction between breast cancer and severe mental illness [56]. 


\section{Discussion}

It has been estimated that more than half the burden of cancer could be prevented by applying knowledge that is already available $[57,58]$. This estimate is especially applicable to women with mental illness who continue to bear a disproportionate cancer burden in terms of stage of illness at diagnosis and of mortality from their disease. One extra explanation for both increased incidence and increased mortality of breast cancer in this population is comorbidity - comorbid cardiovascular and metabolic illness resulting indirectly from mental illness (e.g. from sedentary habits, smoking, substance abuse, poor diet) and its treatment (e.g. antipsychotic-induced obesity and hyperprolactinemia) $[59,60]$. Prevention and treatment of co-morbidity is essential in this population. Finding ways to increase the breast cancer screening rate is also imperative. A recent Cochrane review concluded that there was "no RCT evidence for any method of encouraging cancer screening uptake in people with SMI" [61]. The Druss, et al. 2010 study [62], however, did show that two nurses in a community mental health setting who followed a manualized protocol improved the use of preventive care services almost three fold across the cancer care continuum of screening, diagnosis, treatment, and end-of-life care. The protocol included the provision of booklets containing medical information. It used motivational interviewing techniques, individual action plans, referrals to appropriate specialists, and coaching on how to effectively communicate with physicians. The nurses accompanied patients to medical visits whenever necessary. This was not a randomized controlled trial but, nevertheless, seems to show that actively engaging patients and involving them in decision-making about their health can overcome apathy. Cancer literacy is acknowledged to be vital, for both patients and care providers $[36,63]$. Cognitive challenges in patients with $\mathrm{SMI}$ can be overcome and their stress alleviated by repeated explanations and accompaniment to preventive health appointments. Decision aids have been shown to increase knowledge, lessen distress, and induce realistic expectations in patients facing difficult medical choices [47]. Despite significant challenges, a close collaboration between oncology and mental health should, according to this review of the pertinent literature, be able to ensure that women with severe mental illnesses receive high-quality cancer care $[64,65]$.

\section{Conclusion}

This review has focused on breast cancer in women with serious mental illness such as schizophrenia and psychotic disorders related to schizophrenia. There is a high incidence of breast cancer in these women, a relatively low uptake of cancer screening, overly long delays in seeking and obtaining appropriate treatment, and unnecessarily high mortality. Medical options for these women are often constrained by limited financial resources and exclusion from clinical trials. Potential reasons have been discussed: Poverty, stigma, lifestyle factors, cognitive and motivational issues, underdeveloped social networks, and co-morbid conditions that are induced, in part, by the treatments currently used for psychotic conditions.

\section{References}

1. Mood C, Jonsson JP (2016) The social consequences of poverty: An empirical test on longitudinal data. Soc Indic Res 127: 633-652.

2. Corrigan $P$ (2004) How stigma interferes with mental health care. Am Psychol 59: 614-625.

3. Palumbo C, Volpe U, Matanov A, Priebe S, Giacco D (2015) Social networks of patients with psychosis: A systematic review. BMC Res Notes 8: 560.

4. Priebe S, Omer S, Giacco D, Slade M (2014) Resource-oriented therapeutic models in psychiatry: Conceptual review. Br J Psychiatry 204: 256-261.

5. Pouget JG, Gonçalves VF, Schizophrenia Working Group of the Psychiatric Genomics Consortium, Spain SL, Finucane HK, et al. (2016) Genome-wide association studies suggest limited immune gene enrichment in schizophrenia compared to 5 autoimmune diseases. Schizophr Bull 42: 1176-1184.

6. Rado J (2017) The complex inter-relationship between diabetes and schizophrenia. Curr Diabetes Rev 13: 195-212.

7. Nesväg R, Knudsen GP, Bakken IJ, Høye A, Ystrom E, et al. (2015) Substance use disorders in schizophrenia, bipolar disorder, and depressive illness: A registry-based study. Soc Psychiatry Psychiatr Epidemiol 50: 1267-1276.

8. Dickerson F, Stallings $C R$, Origoni AE, Vaughan C, Khushalani S, et al. (2013) Cigarette smoking among persons with schizophrenia or bipolar disorder in routine clinical settings, 1999-2011. Psychiatr Serv 64: 44-50.

9. Soyka M, Kagerer S, Brunnauer A, Laux G, Möller HJ (2005) Driving ability in schizophrenic patients: Effects of neuroleptics. Int J Psychiatry Clin Pract 9: 168-174.

10. Desmarais SL, Van Dorn RA, Johnson KL, Grimm KJ, Douglas KS, et al. (2014) Community violence perpetration and victimization among adults with mental illnesses. Am J Public Health 104: 2342-2349.

11. Green MF, Horan WP, Lee J (2015) Social cognition in schizophrenia. Nat Rev Neurosci 16: 620-631.

12. Hooker CI, Tully LM, Verosky SC, Fisher M, Holland C, et al. (2011) Can I trust you? Negative affective priming influences social judgments in schizophrenia. J Abnorm Psychol 120: 98-107.

13. De Hert M, Detraux J, van Winkel R, Yu W, Correll CU (2011) Metabolic and cardiovascular adverse effects associated with antipsychotic drugs. Nat Rev Endocrinol 8: 114-126.

14. Bitter I, Czobor P, Borsi A, Fehér L, Nagy BZ, et al. (2017) Mortality and the relationship of somatic comorbidities to mortality in schizophrenia. A nationwide matched-cohort study. Eur Psychiatry 45: 97-103.

15. Liu NH, Daumit GL, Dua T, Aquila R, Charlson F, et al. (2017) Excess mortality in persons with severe mental disorders: A multilevel intervention framework and priorities for clinical practice, policy and research agendas. World Psychiatry $16: 30-40$. 
16. Agay N, Flaks-Manov N, Nitzan U, Hoshen MB, Levkovitz Y, et al. (2017) Cancer prevalence in Israeli men and women with schizophrenia. Psychiatry Res 258: 262-267.

17. Crump C, Winkleby MA, Sundquist K, Sundquist J (2013) Comorbidities and mortality in persons with schizophrenia: A Swedish national cohort study. Am J Psychiatry 170: 324333.

18. Torre LA, Bray F, Siegel RL, Ferlay J, Lortet-Tieulent J, et al. (2015) Global cancer statistics, 2012. CA Cancer J Clin 65: 87-108.

19. Druss BG, Rosenheck RA, Desai MM, Perlin JB (2002) Quality of preventive medical care for patients with mental disorders. Med Care 40: 129-136.

20. Mitchell AJ, Malone D, Doebbeling CC (2009) Quality of medical care for people with and without comorbid mental illness and substance misuse: Systematic review of comparative studies. Br J Psychiatry 194: 491-499.

21. Rahman T, Clevenger CV, Kaklamani $V$, Lauriello J, Campbell A, et al. (2014) Antipsychotic treatment in breast cancer patients. Am J Psychiatry 171: 616-621.

22. Seeman MV (2011) Preventing breast cancer in women with schizophrenia. Acta Psychiatr Scand 123: 107-117.

23. Wu Chou Al, Wang YC, Lin CL, Kao CH (2017) Female schizophrenia patients and risk of breast cancer: A population-based cohort study. Schizophr Res 188: 165-171.

24. Jensen LF, Pedersen AF, Bech BH, Andersen B, Vedsted $P$ (2016) Psychiatric morbidity and non-participation in breast cancer screening. Breast 25: 38-44.

25. Mitchell AJ, Pereira IE, Yadegarfar M, Pepereke S, Mugadza V, et al. (2014) Breast cancer screening in women with mental illness: Comparative meta-analysis of mammography uptake. Br J Psychiatry 205: 428-435.

26. Thomas M, James M, Vittinghoff E, Creasman JM, Schillinger D, et al. (2017) Mammography among women with severe mental illness: Exploring disparities through a large retrospective cohort study. Psychiatr Serv.

27. Woodhead C, Cunningham R, Ashworth M, Barley E, Stewart RJ, et al. (2016) Cervical and breast cancer screening uptake among women with serious mental illness: A data linkage study. BMC Cancer 16: 819.

28. Fujiwara M, Inagaki M, Nakaya N, Fujimori M, Higuchi Y, et al. (2017) Cancer screening participation in schizophrenic outpatients and the influence of their functional disability on the screening rate: A cross-sectional study in Japan. Psychitary Clin Neurosci.

29. Hartmann MN, Kluge A, Kalis A, Mojzisch A, Tobler PN, et al. (2015) Apathy in schizophrenia as a deficit in the generation of options for action. J Abnorm Psychol 124: 309-318.

30. Chadwick A, Street C, McAndrew S, Deacon M (2012) Minding our own bodies: Reviewing the literature regarding the perceptions of service users diagnosed with serious mental illness on barriers to accessing physical health care. Int J Ment Health Nurs 21: 211-219.

31. Asgari R, Naderi R, Wisnivesky J (2017) Opt-out patient navigation to improve breast and cervical cancer screening among homeless women. J Women Health (Larchmt) 26: 999-1003.

32. Khaliq W, Landis R, Wright SM (2017) Improving breast cancer screening adherence among hospitalized women. J Womens Health (Larchmt) 26: 1094-1098.

33. Clifton A, Burgess C, Clement S, Ohlsen R, Ramluggun $P$, et al. (2016) Influences on uptake of cancer screening in mental health service users: A qualitative study. BMC Health Serv Res 16: 257.

34. Sharp PC, Michielutte R, Freimanis R, Cunningham L, Spangler J, et al. (2003) Reported pain following mammography screening. Arch Intern Med 163: 833-836.

35. Jones S, Howard L, Thornicroft G (2008) 'Diagnostic overshadowing': Worse physical health care for people with mental illness. Acta Psychiatr Scand 118: 169-171.

36. Irwin KE, Henderson DC, Knight BA, Pirl WF (2014) Cancer care for individuals with schizophrenia. Cancer 120: 323-334.

37. Lord O, Malone D, Mitchell AJ (2010) Receipt of preventive medical care and medical screening for patients with mental illness: A comparative analysis. Gen Hosp Psychiatry 32: $519-543$

38. Gabai-Kapara E, Lahad A, Kaufman B, Friedman E, Segev $S$, et al. (2014) Population-based screening for breast and ovarian cancer risk due to BRCA1 and BRCA2. Proc Natl Acad Sci U S A 111: 14205-14210.

39. King MC, Levy-Lahad E, Lahad A (2014) Population-based screening for BRCA1 and BRCA2: 2014 Lasker Award. JAMA 312: 1091-1092.

40. Andersen MR, Thorpe J, Buist DS, Beatty JD, Watabayashi $\mathrm{K}$, et al. (2016) Cancer risk awareness and concern among women with a family history of breast or ovarian cancer. Behav Med 42: 18-28.

41. Ackerman MG, Shapiro PA, Coe A, Trivedi MS, Crew KD (2017) The impact of mental illness on uptake of genetic counseling for hereditary breast cancer and ovarian cancer in a multiethnic cohort of breast cancer patients. Breast $J$ 23: $519-524$.

42. Butow P, Phillips KA (2016) Medication to reduce breast cancer risk: Why is uptake low? Ann Oncol 27: 553-554.

43. Howard AF, Balneaves LG, Kazanjian A (2013) Mastectomy to prevent breast cancer: Psychosocial aspects of women's decision-making. In: Carr BI, Steel JL, Psychological Aspects of Cancer. Springer, New York, 65-67.

44. Sanati A, Kyratsous M (2015) Epistemic injustice in assessment of delusions. J Eval Clin Pract 21: 479-485.

45. Kidd IJ, Carel H (2017) Epistemic injustice and illness. J Appl Philos 34: 172-190.

46. Thorat MA, Cuzick J (2017) Preventing invasive breast cancer using endocrine therapy. Breast 34: S47-S54.

47. Padamsee TJ, Wills CE, Yee LD, Paskett ED (2017) Decision making for breast cancer prevention among women at elevated risk. Breast Cancer Res 19: 34.

48. Smith SG, Sestak I, Forster A, Partridge A, Side L, et al. (2016) Factors affecting uptake and adherence to breast cancer chemoprevention: A systematic review and meta-analysis. Ann Oncol 27: 575-590.

49. Corrigan PW, Mittal D, Reaves CM, Haynes TF, Han X, et al. (2014) Mental health stigma and primary health care decisions. Psychiatry Res 218: 35-38.

50. Iglay K, Santorelli ML, Hirshfield KM, Williams JM, Rhoads GG, et al. (2017) Diagnosis and treatment delays among elderly breast cancer patients with pre-existing mental illness. Breast Cancer Res Treat 166: 267-275.

51. Chang CK, Hayes RD, Broadbent MT, Hotopf M, Davies E, et al. (2014) A cohort study on mental disorders, stage of cancer at diagnosis and subsequent survival. BMJ Open 4: e004295. 
52. Kisely S, Crowe E, Lawrence D (2013) Cancer-related mortality in people with mental illness. JAMA Psychiatry 70: 209-217.

53. Farasatpour $M$, Janardhan $R$, Williams $C D$, Margenthaler JA, Virgo KS, et al. (2013) Breast cancer in patients with schizophrenia. Am J Surg 206: 798-804.

54. Hwang M, Farasatpour M, Williams CD, Margenthaler JA, Virgo KS, et al. (2012) Adjuvant chemotherapy for breast cancer in patients with schizophrenia. Oncol Lett 3: 845-850.

55. Björkenstam E, Ljung R, Burström B, Mittendorfer-Rutz E, Hallqvistet J, et al. (2012) Quality of medical care and excess mortality in psychiatric patients a nationwide register-based study in Sweden. BMJ Open 2: e000778.

56. Ribe AR, Laurberg T, Laursen TM, Charles M, Vedsted $P$, et al. (2016) Ten-year mortality after a breast cancer diagnosis in women with severe mental illness: A Danish population-based cohort study. PLoS One 11: e0158013.

57. Colditz GA, Wolin KY, Gehlert S (2012) Applying what we know to accelerate cancer prevention. Sci Transl Med 4: 127.

58. Emmons KM, Colditz GA (2017) Realizing the potential of cancer prevention - The role of implementation science. $\mathrm{N}$ Engl J Med 376: 986-990.

59. Han CJ, Korde LA, Reding S, Allot K, Van Doren M, et al. (2017) Investigation of a lifestyle intervention in women at high risk of breast cancer. West J Nurs Res 1: 193945917697227.

60. Zonderman AB, Ejiogu N, Norbec J, Evans MK (2014) The influence of health disparities on targeting cancer prevention efforts. Am J Prev Med 46: S87-S97.

61. Barley EA, Borschmann RD, Walters P, Tylee A (2013) Interventions to encourage uptake of cancer screening for people with severe mental illness. Cochrane Database Syst Rev.

62. Druss BG, von Esenwein SA, Compton MT, Rask KJ, Zhao L, et al. (2010) The Primary Care Access Referral, and Evaluation (PCARE) study: A randomized trial of medical care management for community mental health settings. Am J Psychiatry 167: 151-159.

63. Young B, Bedford L, Kendrick D, Vedhara K, Robertson JFR, et al. (2017) Factors influencing the decision to attend screening for cancer in the UK: A meta-ethnography of qualitative research. J Public Health (Oxf) 9: 1-25.

64. Bevers TB, Ward JH, Arun BK, Colditz GA, Cowan KH, et al. (2015) Breast cancer risk reduction, version 2. 2015. J Natl Compr Canc Netw 13: 880-915.

65. Howard LM, Barley EA, Davies E, Rigg A, Lempp H, et al. (2010) Cancer diagnosis in people with severe mental illness: Practical and ethical issues. Lancet Oncol 11: 797-804. 